\title{
JULIO RUELAS Y FÉLICIEN ROPS
}

\section{Por José Rojas Gatcidueñas}

El muy limitado y escueto propósito de esta nota es el de apuntar, o más bien subrayar, una de las raíces formales del arte de Julio Ruelas. Queda expresado así, desde la frase inicial, para que el lector no espere más de estas líneas, ni se distraiga con ellas si tan modesta finalidad no es de su interés.

De lo que se ha escrito acerca de Julio Ruelas (cuya bibliografía se encontrará simplemente revisando los autores que luego citaré), entresaco estos párrafos que a mi propósito atañen:

Para conmemorar el cincuentenario de la muerte de Ruelas, se publicaron estas líneas de Salvador Toscano, en 1957:

Enviado por su madre a Europa, hacia 1891 pudo ingresar en la Escucla de Arte de la Universidad de Karlsruhe, Alemania, en donde bajo la dirección del pintor Meyerbeer continuó sus estudios de dibujo y de pintura $y$ en donde recibió una influencia fundamental en su vida, la del pintor alemán Arnold Böklin. .1

Diez años más tarde (aunque ya había tratado el asunto en obras anteriores), dijo Justino Fernández de Julio Ruelas:

Pasó a Europa en 1891 y estudió en la Escuela de Arte de la Universidad de Karlsruhe, al lado de Meyerbeer; fue en Alemania donde recibió una influencia importante en su vida, la del pintor suizo Amold Böklin...2

Un año después publicó Crespo de la Serna un estudio en donde se encuentran más amplias referencias a los antecedentes artísticos que in-

I Salvador Toscano, "Homenaje a Julio Ruelas. 1870-1907", en Suplemento del Boletín Bibliografico de la Secretaria de Hacienda y Crédito Público. México, domingo 15 de septiembre de 1957. Con tal fecha, es indudable que este articulo es reproducción de otro anterior, puesto que Salvador Toscano murió en septiembre de 1949. El citado Boletin Bibliogrdfico de la Secretaria de Hacienda no menciona de dónde tomó lo que alli publica, pero eso, para el caso actual, no tiene mayor importancia; probablemente procede de otros articulos de Salvador Toscano en el suplemento dominical de $E l$ Nacional o de un folleto o catálogo de Ruelas que la Secretaria de Educación Pública editó hacia 1947.

2 Justino Fernández. El Arte del Siglo $\overline{\mathbf{x}} \mathbf{1 x}$ en México. Universidad Nacional Autónoma de México. Instituto de Investigaciones Estéticas. Imprenta Universitaria, México, 1967, p. 144. 
fluyeron en la formación de Ruelas, que a su juicio fueron casi exclusivamente alemanes, aunque en líneas finales del ensayo alude a otras fuentes; he aquí esos párrafos:

En la Escuela de Arte de la Universidad de Karlsruhe, a través del pintor Meyerbeer, su maestro inmediato, se ejercita en una rigurosa disciplina aca. démica. Adquiere la sólida técnica que concentra sus actividades en Munich, antes del movimiento renovador de la llamada Sezession, en la que se rastrean modalidades monacenses o vienesas de un Art nouveau con perfiles un tanto distintos de lo francés: el llamado Jugendstil, que Ruelas ha de prodigar sobre todo en sus dibujos y grabados.

...Con toda razón se ha señalado en la obra de Ruelas la huella de maestros alemanes de ese tiempo... La sombra de Lenbach, uno de los principales maestros de Munich, la costumbre del taller de desactualizar el modelo echándole encima un atuendo nada burgués, más bien de otras épocas... presentan rasgos inconfundibles de tales influencias.

En sus temas líricos, como "La domadora", "El ahorcado", "El sátiro ahogado", "La araña", está presente su simpatia por el suizo-alemán Arnold Boecklin. En la justeza y flexibilidad de su dibujo del cuerpo humano, que ya poseía desde San Carlos, son harto visibles similitudes con Franz von Stuck y Fritz Schider, maestros consumados en anatomía. ${ }^{3}$

Y páginas adelante, ya en conclusiones finales sobre el arte de Julio Ruelas, el propio Crespo señala:

En no pocos casos su fantasía, su temperatura ardiente, su desasosiego, su osadia, recuerdan el trazo febril, mordaz, inconforme, de gran lirismo trágico, de un Goya estilizado en su metástasis a través del belga Felicien Rops. Por la elegancia y rotundidad de la sinuosa y atormentada linea que en ellos se advierte, está más cerca de los ilustrados del Simplicissimus, como el travieso Kley, que de los maestros franceses de la misma época, como por ejemplo un Forain. Más bien, tomando en conjunto todo su arte, se rastrean aquí y alli similitudes tácitas con una escuela del siglo xix muy anterior: la de los prerrafaelistas. Al ver ciertas obras de Ruelas, en efecto, recuerda uno a Burne Jones y al jefe de la escuela, Dante Gabriel Rosetti.4

Como se ve, apenas de pasada y ni siquiera directamente, sino en lo que él llama una metástasis de Goya, sólo así menciona a Rops. Y a la verdad que no entiendo lo que quiere decir con este tecnicismo de patología, a menos que haya un lapsus calami y debemos leer "metátesis"; en fin,

3 Jorge J. Crespo de la Serna, Julio Ruelas en la vida y en el arte. Fondo de Cultura Económica, México, 1968, pp. 14-15.

tOp. cil., p. 40. 
parece que la idea era sugerir un cambio o substitución entre Goya y Rops. Pero, insisto, es apenas una alusión y ya se ve cuán oscura.

En cambio, para mí, la relación entre Julio Ruelas y Félicien Rops es clara y evidente, y eso es lo que pretendo señalar en esta nota.

Pero también conviene ubicar a uno y otro artista, para comodidad del lector y aclarar bien las cosas, pues sin hacerlo y sin consultar datos podria alguien —absurda hipótesis- preguntar quién influyó en quién.

He aquí los datos esenciales: Julio Ruelas nació en Zacatecas, en 1870. Traido a México desde niño aquí estudió primeras letras, luego en el Colegio Militar y después en San Carlos, la Escuela Nacional de Artes Plásticas. Prosiguió sus estudios de arte en Alemania, de 1891 a 1895 en que regresa; colabora en la Revista Moderna a partir de enero de 1899; pensionado, vuelve a Europa en 1904, visita varias ciudades de Alemania, Bélgica y Holanda y se radica en París, donde estudia técnicas de grabado. Murió, probablemente de tuberculosis, en París, en septiembre de 1907; yace en el cementerio de Montparnasse bajo un mausoleo, obra de Domínguez Bello.

Félicien-Joseph-Victor Rops nació en Namur el 7 de julio de 1833, es decir, en el corazón de Bélgica y cuando ese país acababa de recuperar su independencia y de constituirse en reino. El padre de Félicien Rops era un industrial de buena posición, fabricante de telas estampadas; el joven Félicien estudió en el colegio de los jesuitas, en Namur y después algunos años en la Universidad de Bruselas.

Rops empezó a publicar caricaturas, generalmente en litografía y a veces en grabado en madera, cuando tenía veinte años de edad. Pero su verdadera carrera artística empieza en 1856, con la fundación del semanario satírico Uylenspiegel; para esa revista y para ilustrar algunos libros produjo, en cuatro o cinco años, unas doscientas litografías, no pocas de mérito.

A partir de 1862 abandonó, salvo raras excepciones, el dibujo litográfico y se fue interesando, cada vez más, por la técnica del aguafuerte y luego por otras maneras del grabado, trabajos que hizo para ilustrar gran número de libros, inclusive las ediciones Poulet-Melassis, que circulaban más o menos clandestinamente, desde 1864 hasta 1869, con temas atrevidamente eróticos.

La década de los setentas, hace precisamente un siglo, y también la siguiente, de los años ochentas, fueron de trabajo intenso y fructifero para Rops, quien ya entonces tenía feliz crédito aun fuera de su patria, 
trabajando para Lemerre y otras famosas editoriales francesas. Hizo entonces innumerables grabados en cobre, al aguafuerte, puntasecas, acuatintas, en barniz blando (llamado barniz suave) y en otras técnicas, obras que se publicaron en portadas, ilustraciones y en importantes publicaciones especiales, como las de un Album de la Sociedad Internacional de Acuafortistas, en 1875.

Al terminar la década de los ochentas su producción disminuyó, y parece que dejó de grabar en los tres o cuatro últimos años de su vida. Murió en agosto de 1898.

Cabe advertir que, aunque Rops fue fundamentalmente grabador, también hizo muchos dibujos que fueron grabados por otros artistas o que se reprodujeron por otros procedimientos. Algunos fueron publicados años después de la desaparición de Félicien Rops.

Dadas, pues, las trayectorias de las vidas de uno y otro artista, nada más lógico que Ruelas haya admirado el arte del extraordinario grabador que fue Rops y lo haya seguido más o menos de cerca en varias ocasiones. Creo que así lo muestran estos cuantos ejemplos que ilustran esta nota, los cuales están tomados del catálogo, en cuatro volúmenes: L'Oeuvre gravé et litographié de Félicien Rops, par Maurice Exsteens, éditions Pellet, Paris, 1928; los números que van al pie, junto al título de la estampa, corresponden a dicho catálogo; los grabados reproducidos son los siguientes:

"No. 305 - La poupée du satyre. Eau-Forte. Paru dans "L'Artiste" en fevrier 1888".

"No. 424 - La Lyre. Vernis-mou". Según la nota, este grabado apa. reció insertado en una muy rara publicación de cuarenta ejemplares, de poesías de Mallarmé, en París, en 1887.

"No. 429 - Le bonheur dans le crime. Vernis-mou". Como en otros casos, el título nada tiene que ver con el asunto del grabado mismo, el cual se hizo para ilustrar una edición de "Les Diaboliques" de Barbey D'Aurevilly.

“No. 435 - La dame au cochon ou Pornokratés. Vernis-mou”. En nota al pie, agrega: "Cette oeuvre, une des plus populaires de l'artiste, a ćté reproduite maintes fois", y menciona un grabado de Gaujeau, dos heliograbados y una gran plancha grabada por A. Bentrand "d'après le dessin original", que también registra el catálogo de Exsteens, con el número 835 , y se reproduce aqul. 
"No. 504.- Curieuse. Eau-forte". Se publicó al frente de la novela "Curieuse", de Joséphin Péladan, en París, 1885.

"No. 516 - Initiation sentimentale. Vernis-mou". Para "Initiation sentimentale en La Décadence Latine" de J. Péladan, Paris, 1887.

"No. 520 - A coeur perdu. Vernis-mou". Para la obra "A coeur perdu en La Décadence Latine" de J. Péladan, París, 1888. Como se ve, el título que lleva este grabado, según el catálogo lo registra, es simplemente el de la obra literaria que ilustra; en realidad, por el asunto, debería llamarse más bien: el árbol del bien y del mal o el árbol de la sabiduria o del fruto prohibido, puesto que así lo indica la leyenda en la filacteria que está entre las ramas, arriba de la cabeza de la figura, donde se lee: Eritis similes Deo.

"No. 853 - La dame au cochon. Gravure, eau-forte et aquatinte, en couleur au repérage. Gravé par A. Bertrand. G. Pellet, éditeur, París, 1896". Es el grabado ya aludido en la nota correspondiente al número 435. El grabador Bertrand procedió con tal honestidad, que conservó hasta la firma de Félicien Rops, en el ángulo inferior izquierdo de la nueva plancha.

"No. 872.- Cocotogratie. Eau-forte en couleaurs. Gravé par A. Bertrand d'après une page de croquis".

Albert Bertrand, parisiense (1854-1912), fue un magnifico grabador, sobre todo en las diversas técnicas de talla dulce; fue extraordinario manejando "ese arte ingrato", como dice un crítico, de lo que llaman en francés gravure en couleur au repérage que, como se sabe, se hace mediante la superposición de varias impresiones de otras tantas planchas según los colores, que deben resultar con "registro" perfecto, de donde la denominación au repérage.

Es evidente la relación entre La dame au cochon de Félicien Rops y La domadora de Julio Ruelas, y más, si cabe, entre Cocotocratie de Rops y la viñeta Sókrates de Ruelas; pero también los restantes grabados, y otros más que hubiera sido prolijo añadir, sugieren bien el conocimiento y aprecio que tuvo Ruelas por la obra de Rops y que no dudó en seguirlo, gustosamente, por la similitud de expresiones que sin duda encontró en Rops y las suyas propias.

Este es el punto final de esta nota, en sus dos sentidos: terminación y propósito. Pero, como suele acostumbrarse en las composiciones musicales, y el uso podría extenderse a las literarias y más bien a las didácticas, creo que conviene hacer aquí un da cappo. 
Al comenzar esta nota dije que quienes han escrito sobre Julio Ruelas pasaron por alto, o casi (en el caso de Crespo), la relación formal entre Ruelas y Félicien Rops. Pero no quiero que, de ningún modo, tal aseveración pueda pensarse como reproche, ni levisimo, a niguno de los tres citados, pues con todos ellos (dos ya ausentes) me ha unido amistad personal, aprecio grande y sincera admiración por sus largas tareas en el estudio del arte. En el caso que nos ocupa me he preguntado ¿por qué la omisión señalada?, y he venido a pensar que la cuestión es muy simple: ¿quién, aquí en México, puede realizar investigaciones exhaustivas -en el supuesto de que eso fuese posible- o, en el sobreentendido común, investigaciones lo más completas que sean realizables? ¿Cómo podrian o podriamos hacerlas si no tenemos ricas bibliotecas (hablo en materia de documentación de artes plásticas), colecciones de revistas, acervos vastos de reproducciones de pinturas y grabados? y cuando, tan excepcional y esporádicamente vamos al extranjero, ¿cómo sería posible, siempre angustiosamente apremiados de tiempo y recursos económicos, detenerse a revisar museos, que generalmente apenas alcanzamos a atisbar, y menos aún enfrascarnos - joh sueños irrealizables! - en las grandes bibliotecas para pasar dias y semanas en la busca y rebusca, estudio y análisis, de las colecciones de grabados de revistas especializadas, de estudios y referencias que darian amplitud y profundidad a tantas preguntas y dudas y cuestiones que todos nos hemos formulado al interesarnos por la historia, valoración y relaciones de los temas artísticos que han suscitado nuestro interés?

Así, pues, todo se reduce, muy probablemente, a que mis estimados amigos y colegas no tuvieron la oportunidad de consultar el catálogo citado y yo sf, (en lo cual no hay ni falta de ellos ni mérito mío), y por eso no precisaron la relación aquí señalada.

Por otra parte, es claro que, vista en su totalidad y sobre todo en profundidad, la obra artística del belga y del mexicano difieren mucho; pero de ningún modo voy a acometer aquí esa cuestión, porque no pretendo estudiar ni a uno ni a otro; estoy seguro de que el aprovechamiento por Julio Ruelas de la obra de Félicien Rops fue parcial y exclusivamente formal, pero eso es, precisamente, lo que he querido mostrar en esta nota. 
DOI: http://dx.doi.org/10.22201/iie.18703062e.1974.43.1000

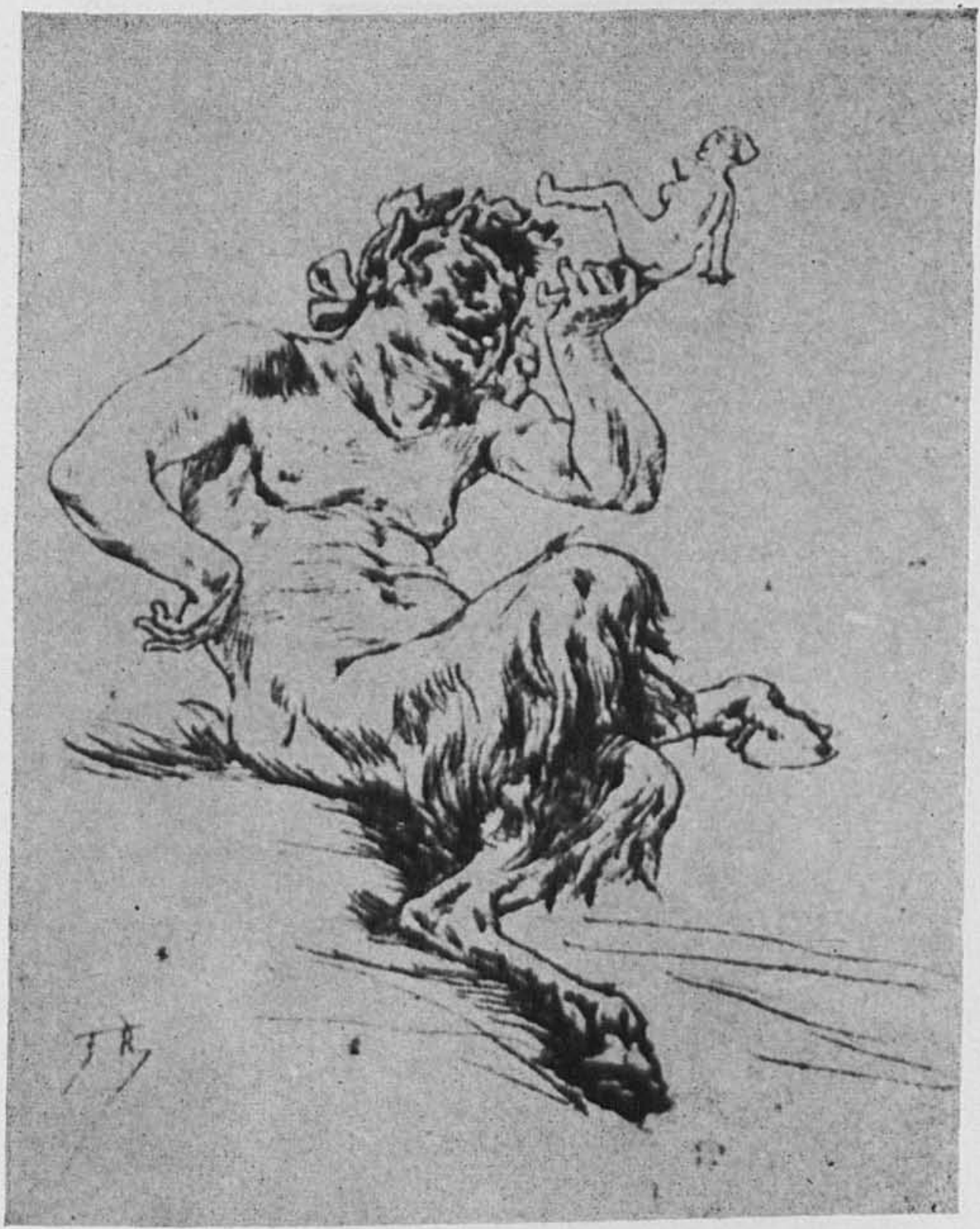

1. Félicien Rops. La poupée du satyre. Aguafuerte 
DOI: http://dx.doi.org/10.22201/iie.18703062e.1974.43.1000

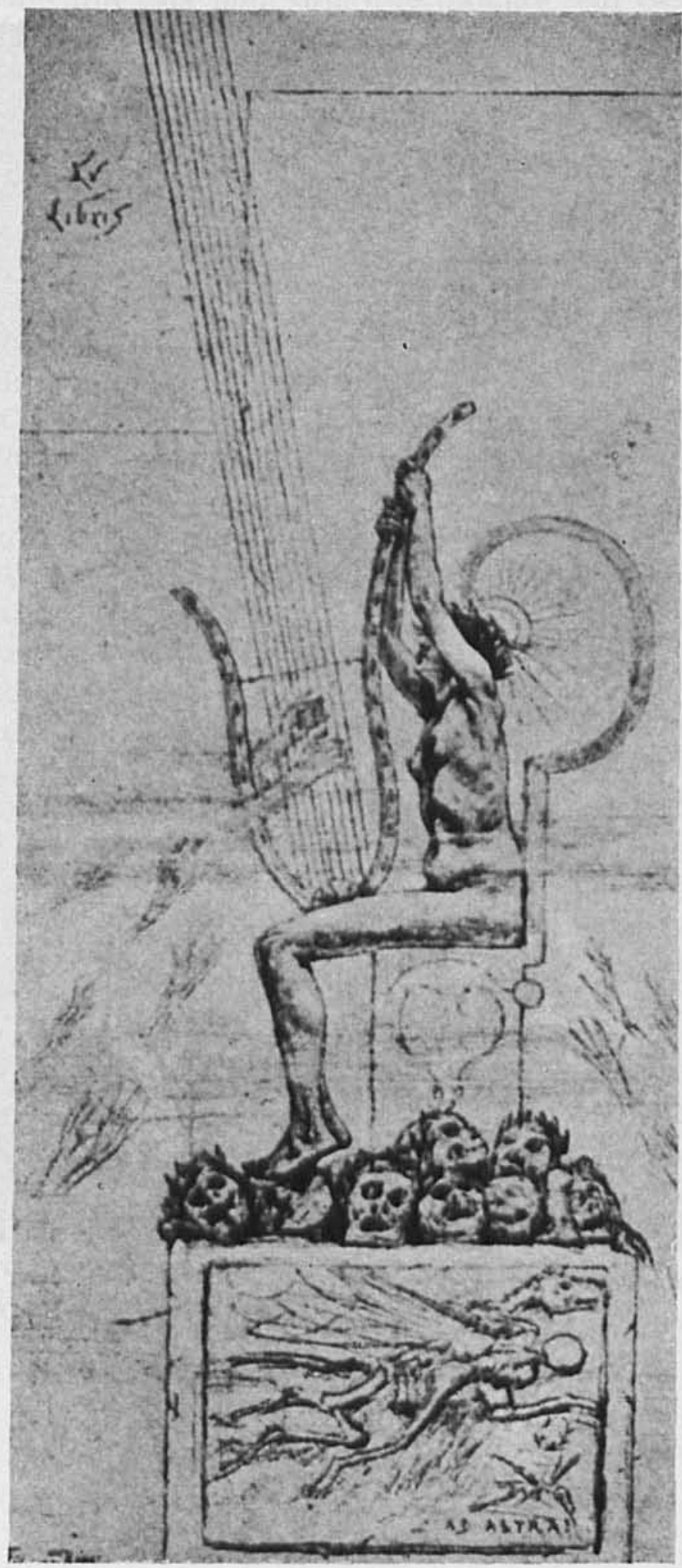

2. Félicien Rops. La lyre. Barniz blando 
DOI: http://dx.doi.org/10.22201/iie.18703062e.1974.43.1000

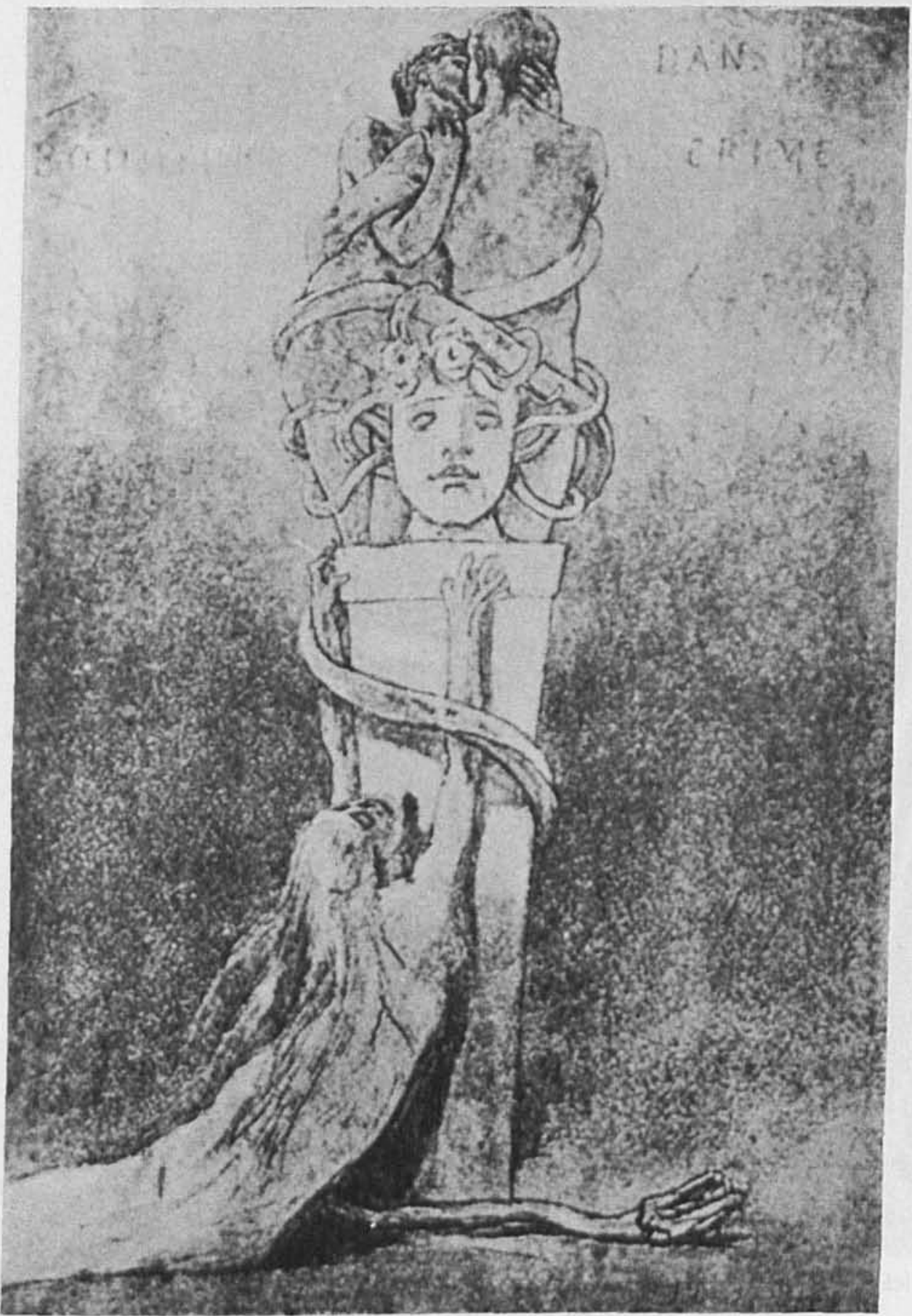

3. Félicien Rops. La bonheur dans le crime. Barniz blando 


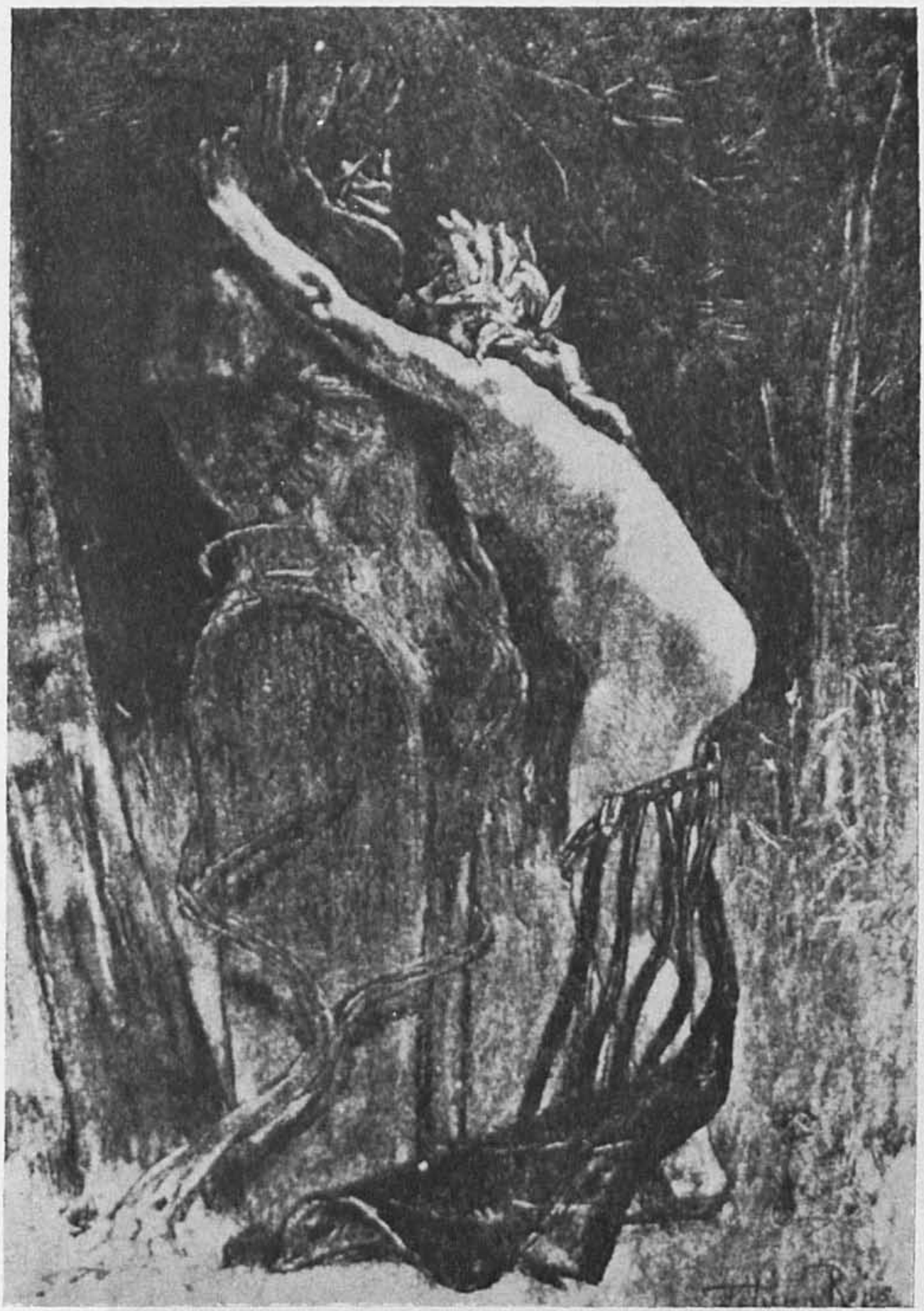

4. Félicien Rops, Curiense. Aguafuerte 
DOI: http://dx.doi.org/10.22201/iie.18703062e.1974.43.1000

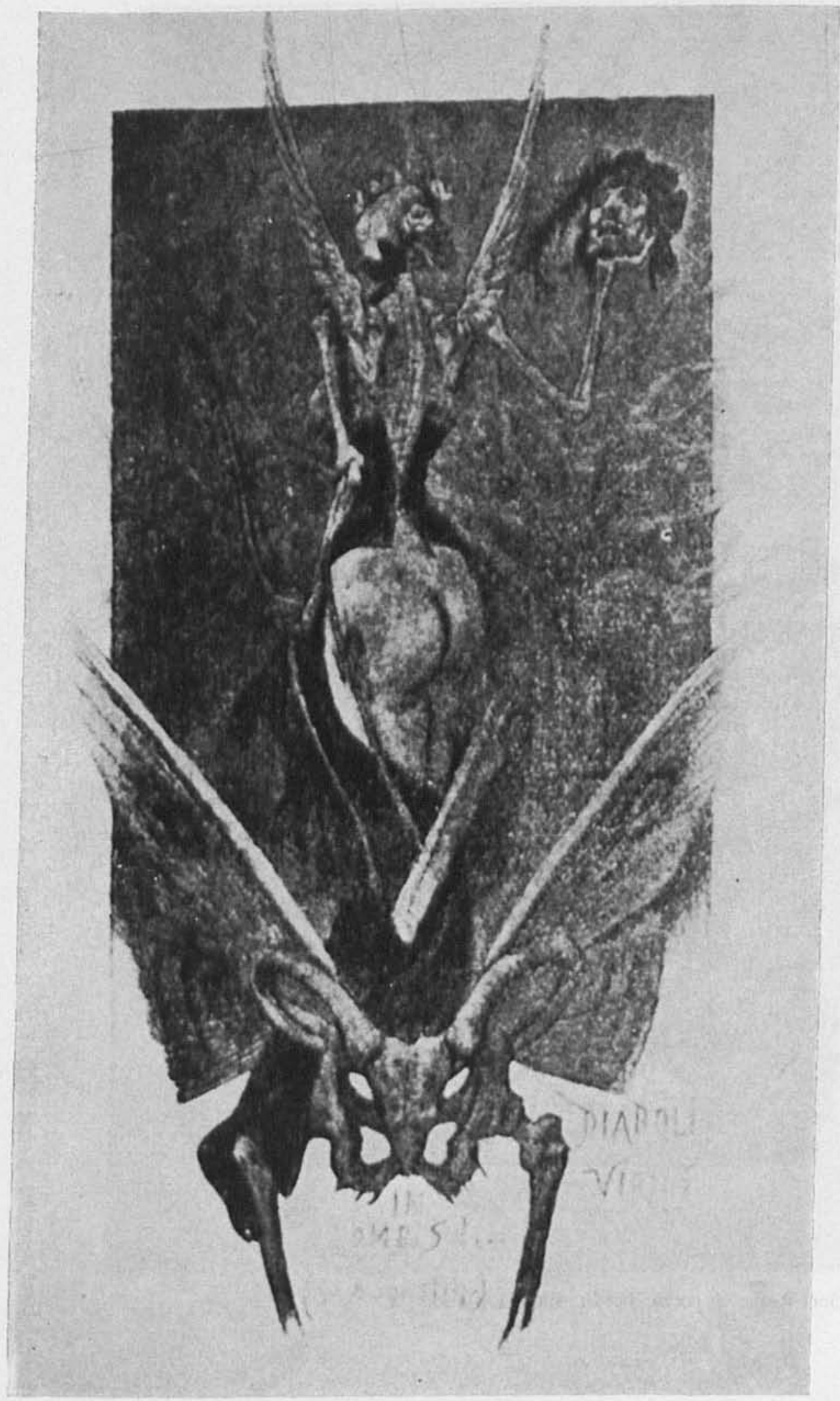

5. Félicien Rops. Mitiation sentimentale. Barniz blando 


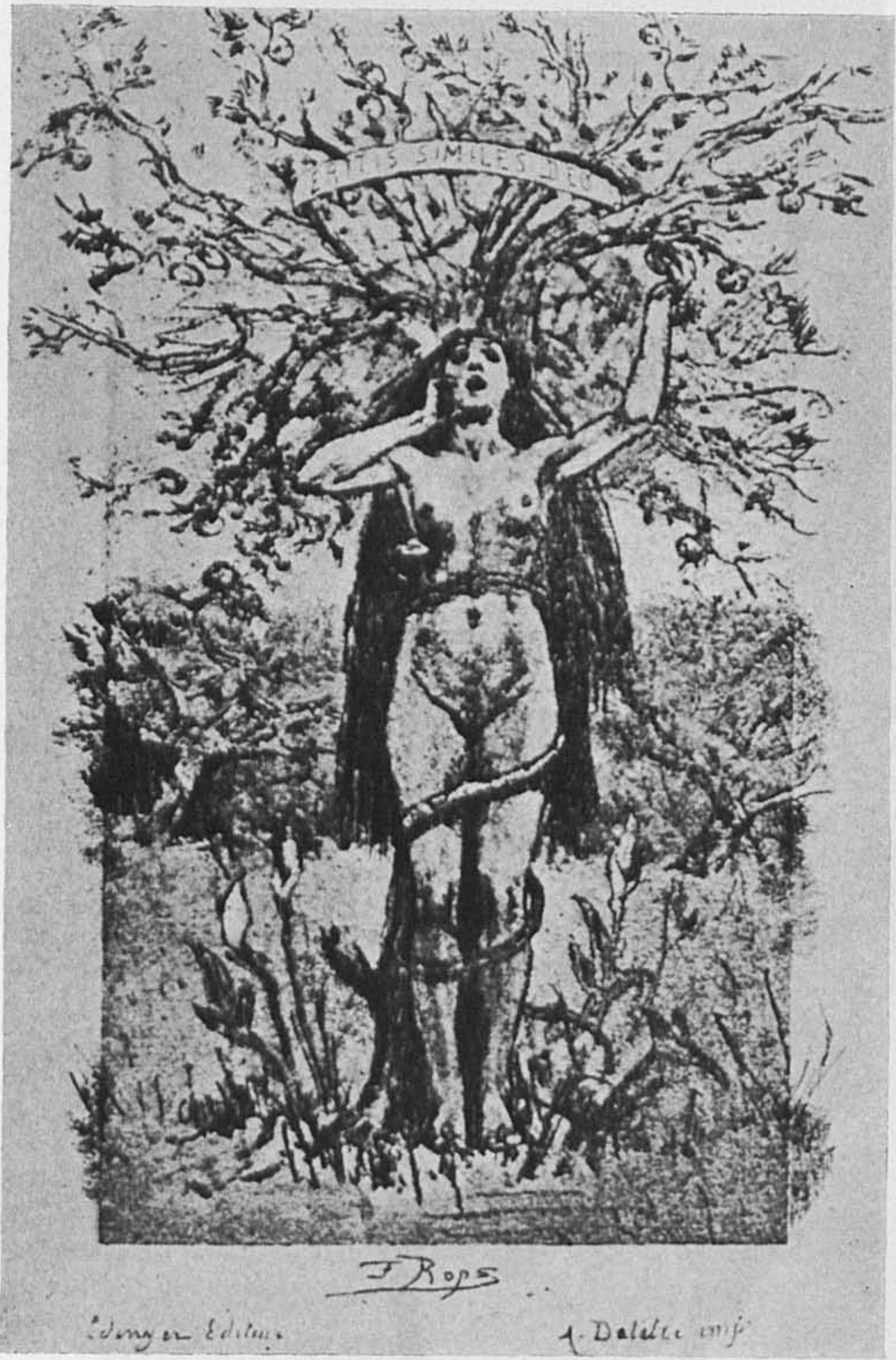

6. Félicien Rops. A coeur perdu. Barniz blando 


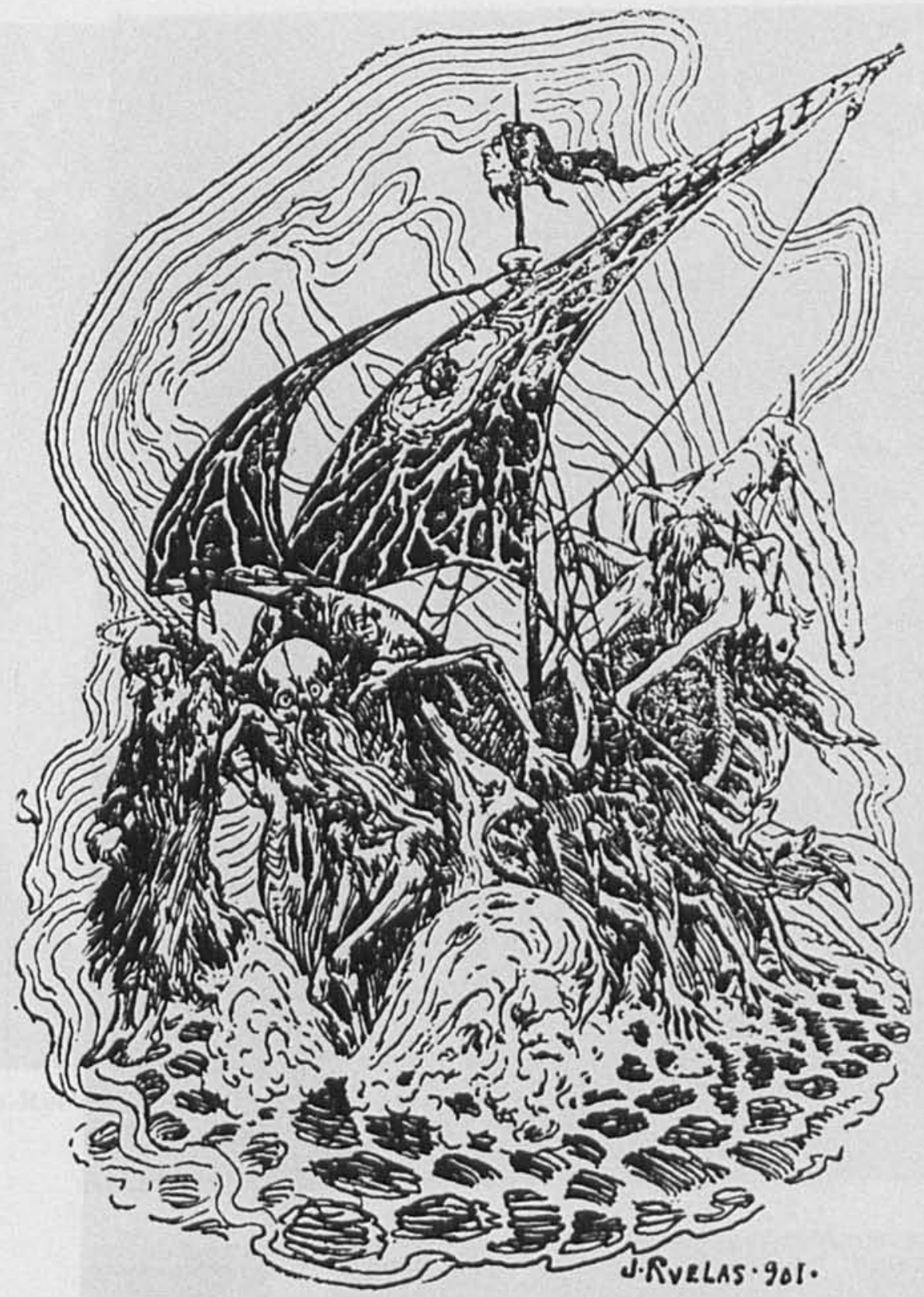

7. Julio Ruelas. Viñeta en Revista Moderna 
DOI: http://dx.doi.org/10.22201/iie.18703062e.1974.43.1000
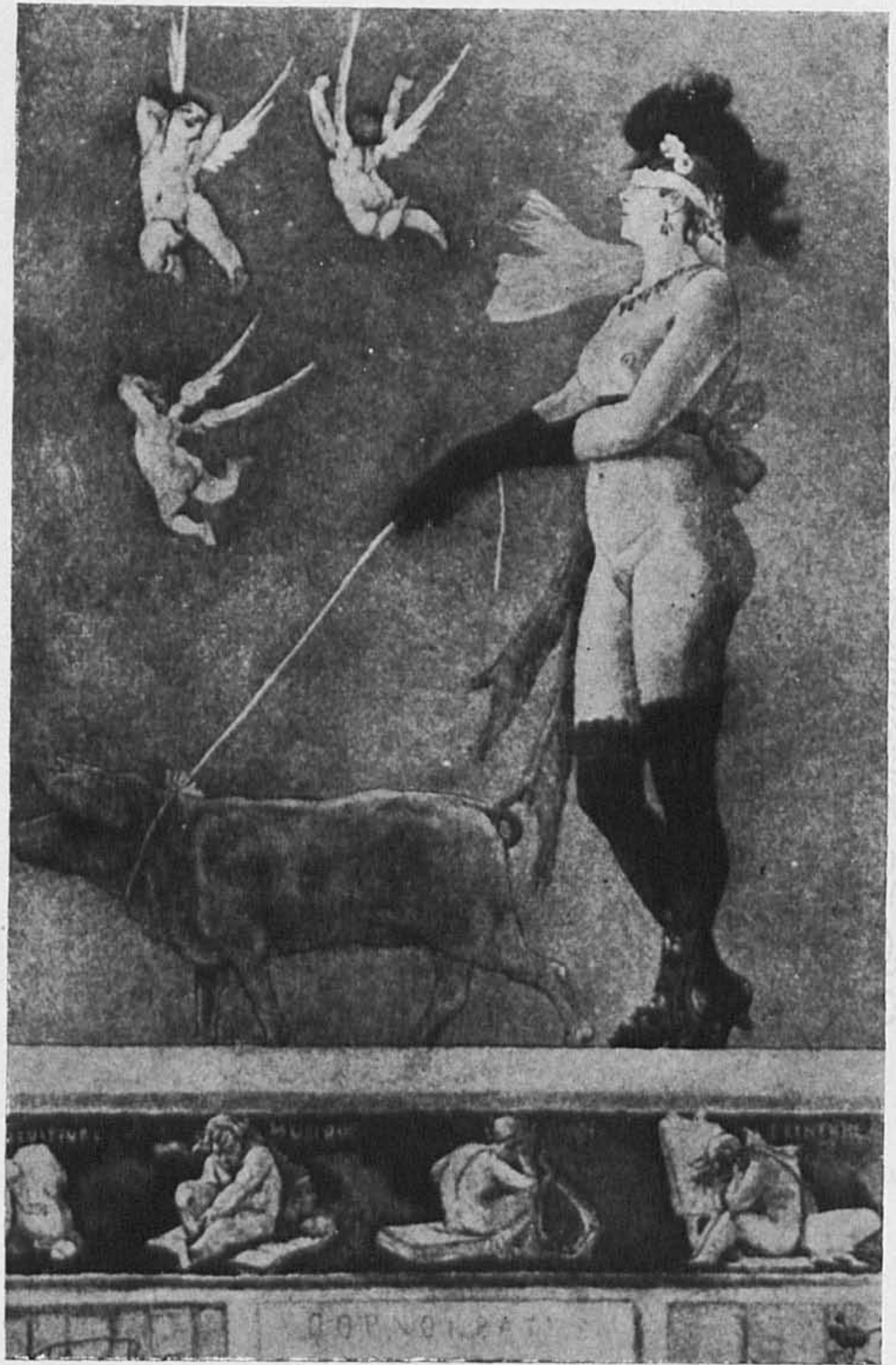

8. Félicien Rops y Albert Bertrand. La dame au cochon. Del original de Rops, regrabado por Bertrand al aguafuerte y acuatinta. 


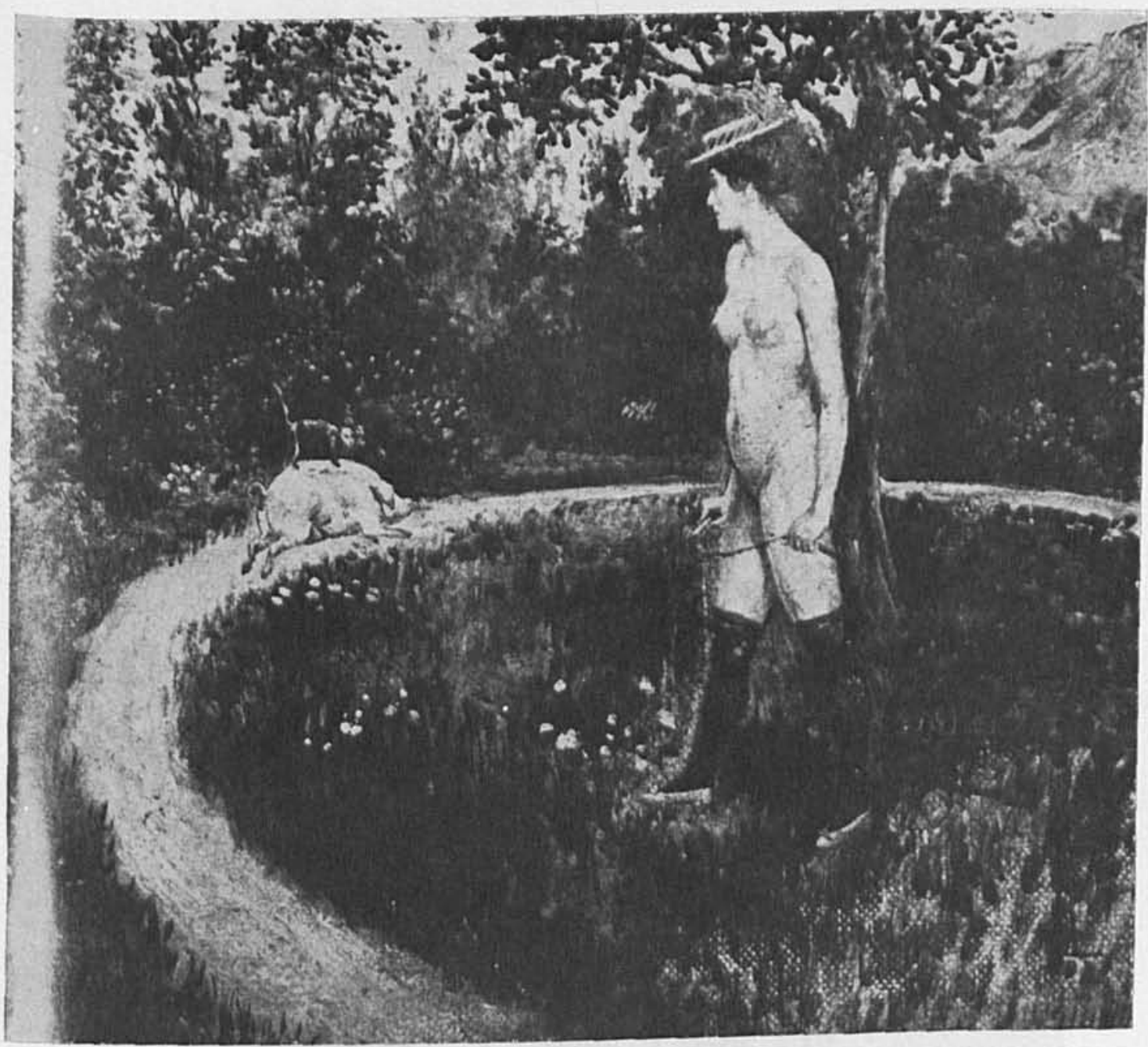

9. Julio Ruelas. La domadora. Oleo sobre tela 
DOI: http://dx.doi.org/10.22201/iie.18703062e.1974.43.1000

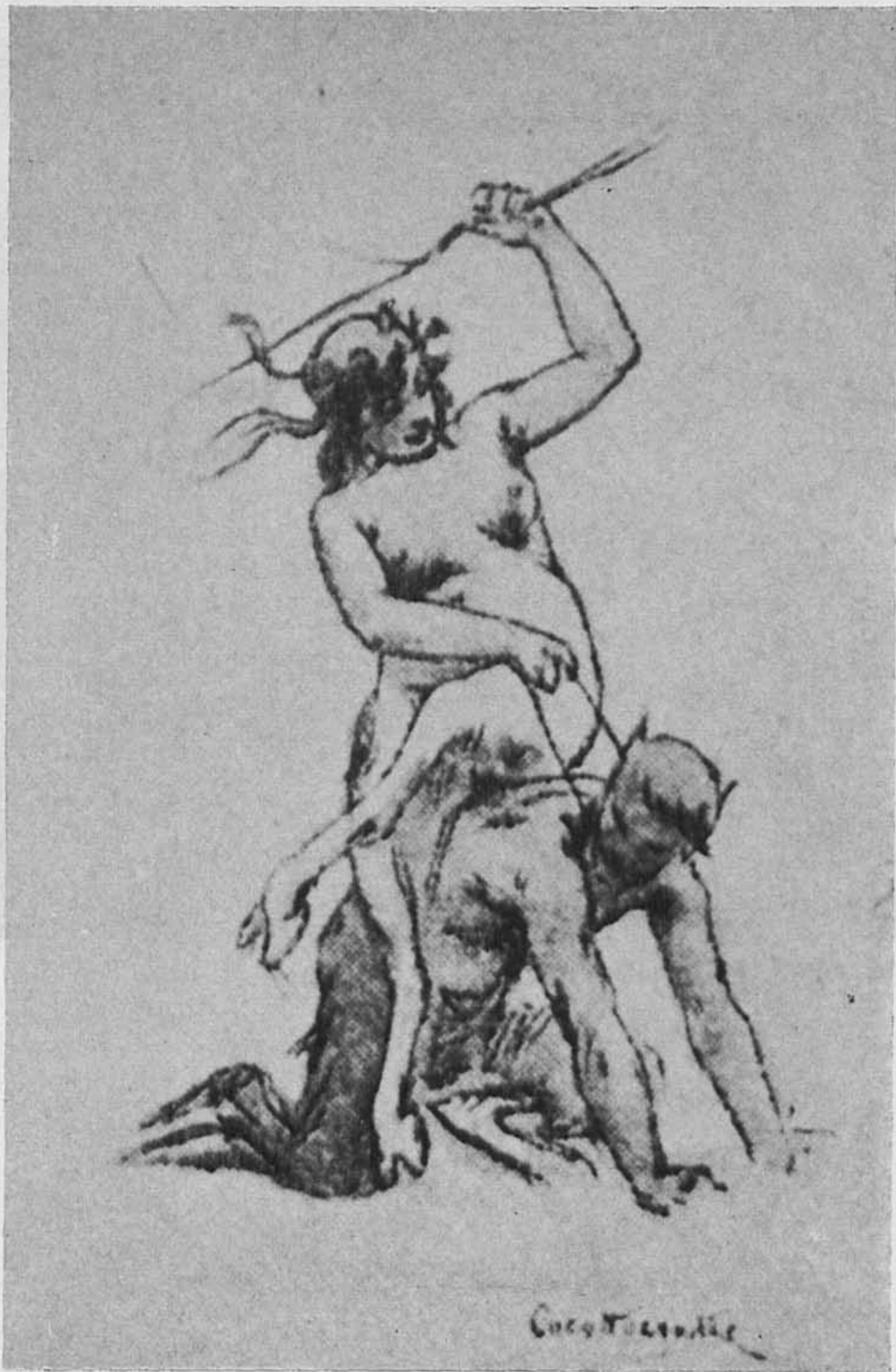

10. Félicien Rops. Cocotocratie. Aguafuerte 


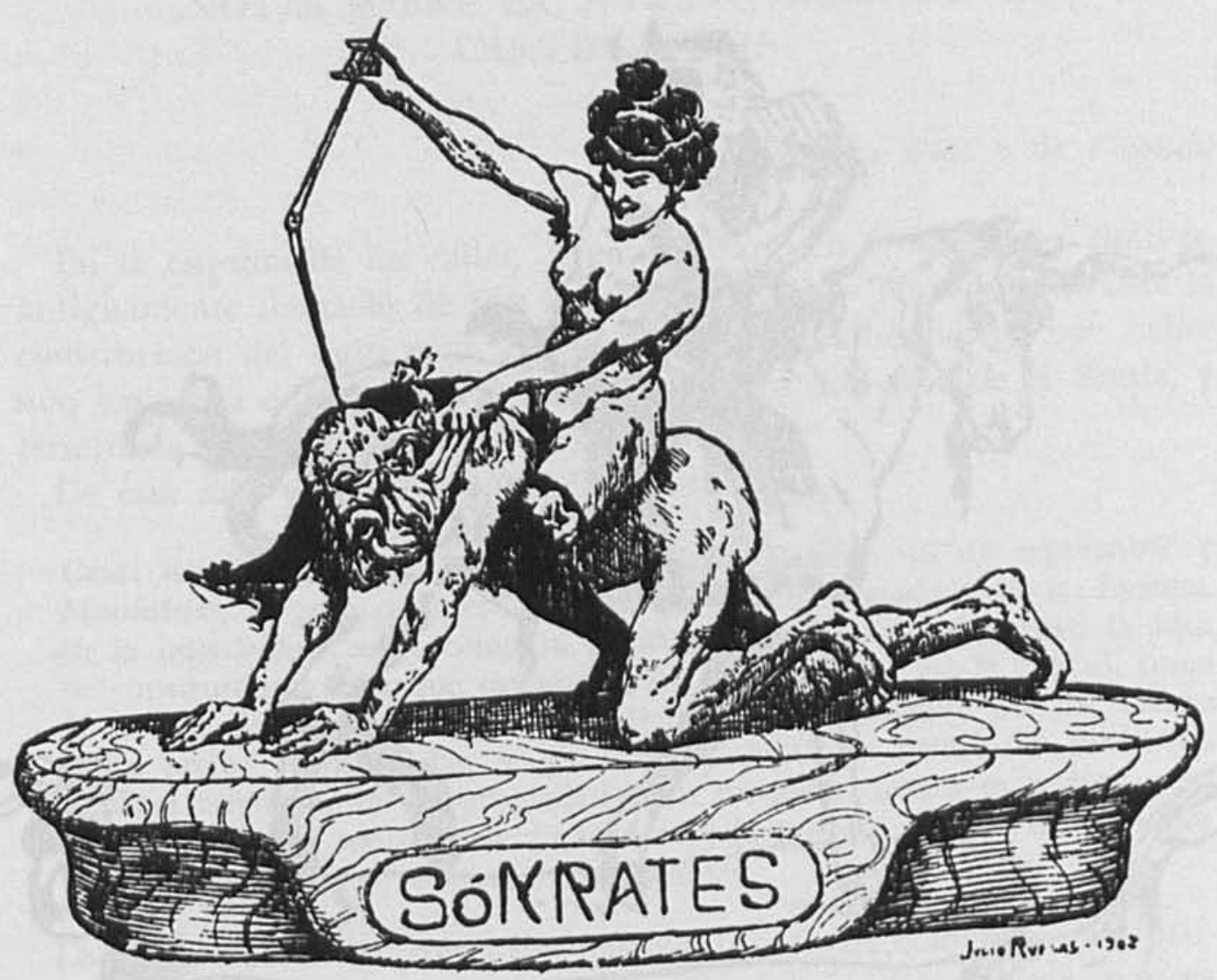

11. Julio Ruelas. Viñeta en la Revista Moderna 


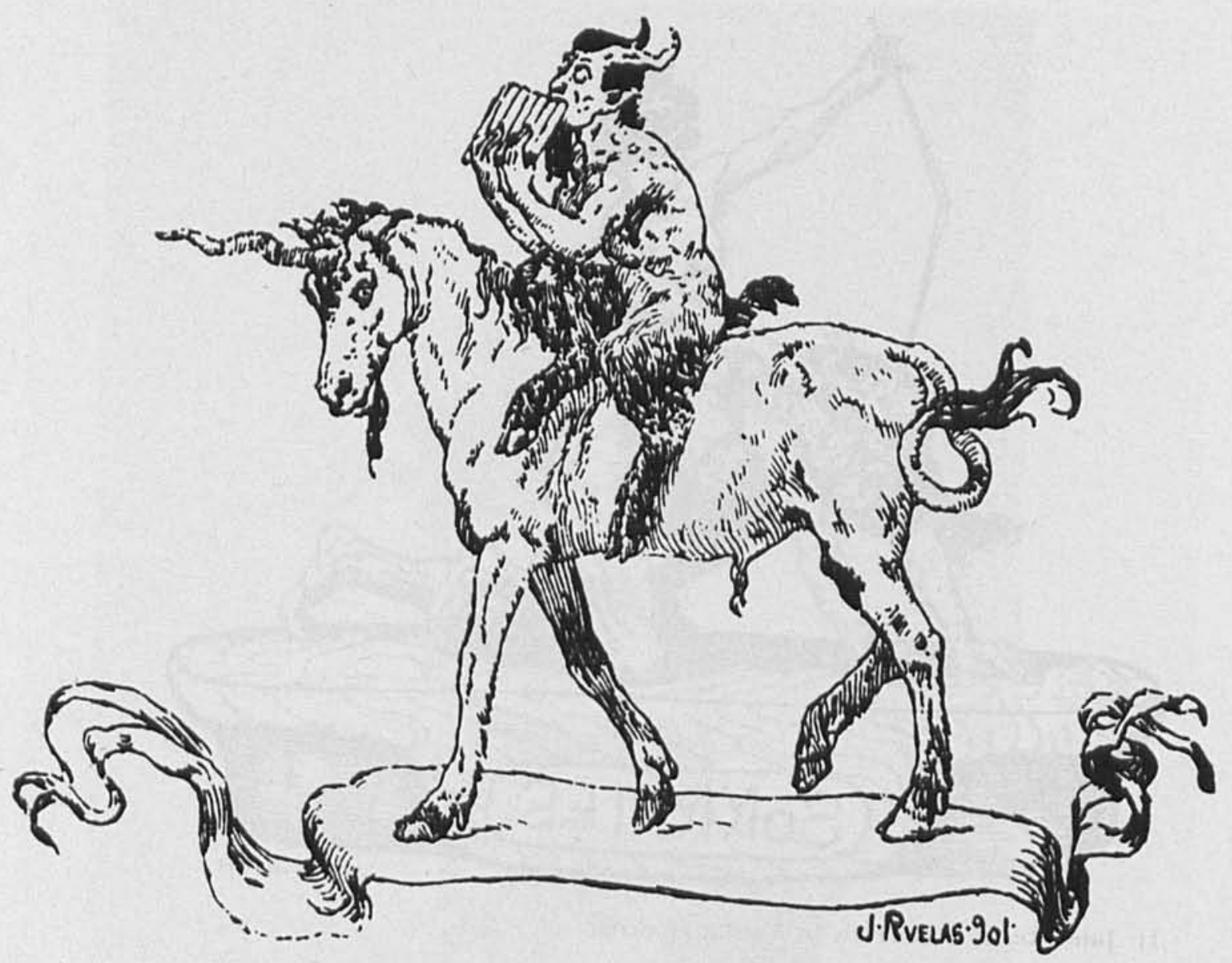

12. Julio Ruelas. Viñeta 